\title{
AUTHOR INDEX FOR VOLUME 88
}

AFKHAMI, M., KARIMI, M. and KHASHYARMANESH, K.; On the regular digraph of ideals of commutative rings

AKBARBAGLU, I. and MAGHSOUDI, S.; Porosity of certain subsets of Lebesgue spaces on locally compact groups

ALZAHARY, T.; Uniqueness of meromorphic functions with weakly weighted sharing

ARENA, O. and GIANNOTTI, C.; Elliptic extensions in the disk with operators in divergence form

BAEK, S., CHOE, I., JUNG, Y., LEE, D. and SEO, J.; Constructions by ruler and compass, together with a fixed conic

BARNSLEY, M. F. and VINCE, A.; The Conley attractors of an iterated function system

BHATT, S. J., DABHI, P. A. and DEDANIA, H. V.; On the $*$-semisimplicity of the $\ell^{1}$-algebra on an abelian $*$-semigroup

BHATTI, M. I.; see MUDDASSAR, $M$.

BORWEIN, D.; Criteria for the sequence of differences of a bounded sequence to be null

BRENT, R. P. and OSBORN, J.-A. H.; Bounds on minors of binary matrices 280

CERONE, P.; see QI, F.

CHANG, M.-C.; Elements of large order in prime finite fields

CHEN, J. and CUI, J.; Two questions of L. Vaš on $*$-clean rings

500

CHEN, S.-C. and LUO, H.; Odd multiperfect numbers

CHEN, SH., PONNUSAMY, S., VUORINEN, M. and WANG, X.; Lipschitz spaces and bounded mean oscillation of harmonic mappings

CHEN, Y.-G.; see REN, X.-Z.

CHOE, I.; see BAEK, S.

CRASMAREANU, M.; see CĂLIN, C.

CUI, J.; see CHEN, J.

CĂLIN, C. and CRASMAREANU, M.; Slant curves and particles in threedimensional warped products and their Lancret invariants

DABHI, P. A.; see BHATT, S. J.

DE KONINCK, J.-M. and KÁTAI, I.; Construction of normal numbers using the distribution of the $k$ th largest prime factor

DEDANIA, H. V.; see BHATT, S. J.

DILONÉ, M. A., GARCÍA-OLIVO, M. and GUTIÉRREZ, J. M.; A note on the semilocal convergence of Chebyshev's method

DING, G.-G. and LI, J.-Z.; Isometries between unit spheres of the $\ell^{\infty}$-sum of strictly convex normed spaces 
DRAGOMIR, S. S.; see QI, F. 309

ESHRAGHI, H.; Existence of almost split sequences via regular sequences 218

FRANCE-JACKSON, H., KHULAN, T. and TUMURBAT, S.; On $\alpha$-like radicals of rings

GABROVŠEK, B.; The categorification of the Kauffman bracket skein module of $\mathbb{R} P^{3}$

GARCÍA-OLIVO, M.; see DILONÉ, M. A.

GIANNOTTI, C.; see ARENA, O.

GIGOŃ, R. S.; Regular congruences on an idempotent-regular-surjective semigroup

GILLESPIE, N. I.; see HAWTIN, D. R.

GOEHLE, G.; Groupoid $C^{*}$-algebras with Hausdorff spectrum

GUTIÉRREZ, J. M.; see DILONÉ, M. A.

HAWTIN, D. R., GILLESPIE, N. I. and PRAEGER, C. E.; Elusive codes in Hamming graphs

HAYAJNEH, S. and KITTANEH, F.; Trace inequalities and a question of Bourin

HE, H.; The Robin problem for the Hénon equation

IRSHAD, W.; see MUDDASSAR, M.

JO, J. H. and LEE, J. B.; A note on free actions of groups on products of spheres

JUNG, Y.; see BAEK, S.

KAMALI, Z. and LASHKARIZADEH BAMI, M.; The multiplier algebra and BSE property of the direct sum of Banach algebras

KAMALOV, F.; The dual structure of crossed product $C^{*}$-algebras with finite groups

KARIMI, M.; see AFKHAMI, M.

KÁTAI, I.; see DE KONINCK, J.-M.

KAWAKUBO, S.; Global solutions of the equation of the Kirchhoff elastic rod in space forms

KEKEÇ, G.; On Mahler's $p$-adic $U_{m}$-numbers

KERR, B.; Solutions to polynomial congruences in well-shaped sets

KHASHYARMANESH, K.; see AFKHAMI, M.

KHULAN, T.; see FRANCE-JACKSON, H.

KIM, D., PARK, Y. K. and PINTÉR, Á.; A diophantine problem concerning polygonal numbers

KIM, Y. C. and SUGAWA, T.; Univalence criteria and analogues of the John constant

KITTANEH, F.; see HAYAJNEH, S. 
KONG, Q. J. and LIU, Q. F.; Conjugacy class size conditions which imply solvability

KOUSHESH, M. R.; One-point extensions and local topological properties

LARKI, H. and RIAZI, A.; Stable rank of Leavitt path algebras of arbitrary graphs

LASHKARIZADEH BAMI, M.; see KAMALI, Z. 250

LEE, D.; see BAEK, S.

LI, J. and WEI, W.; Slide reduction, successive minima and several applications

LEE, J. B.; see JO, J. H.

LI, J. J., ZHANG, G. R. and LING, B.; 1-regular Cayley graphs of valency $7 \quad 480$

LI, J.-Z.; see DING, G.-G.

LIN, S.; see XIE, L.-H.

LING, B.; see LI, J. J.

LIU, Q. F.; see KONG, Q. J.

LUCA, F., OYONO, R. and YALCINER, A.; L-functions of elliptic curves and binary recurrences

LUO, H.; see CHEN, S.-C.

MAGHSOUDI, S.; see AKBARBAGLU, I.

MUDDASSAR, M., BHATTI, M. I. and IRSHAD, W.; Generalisations of integral inequalities of Hermite-Hadamard type through convexity

MUNGKASI, S.; A study of well-balanced finite volume methods and refinement indicators for the shallow water equations

NAM, T. T.; The top left derived functors of the generalised $I$-adic completion

NATH, R. K.; Commutativity degree of a class of finite groups and consequences

OSBORN, J.-A. H.; see BRENT, R. P.

OYONO, R.; see LUCA, F.

PARK, Y. K.; see KIM, D.

PETROVIĆ, LJ. and VALJAREVIĆ, D.; Statistical causality and stable subspaces of $H^{p}$

PINTÉR, Á.; see KIM, D.

POLLACK, P. and SANNA, C.; Uncertainty principles connected with the Möbius inversion formula

PONNUSAMY, S.; see CHEN, SH.

QI, F., CERONE, P. and DRAGOMIR, S. S.; Complete monotonicity of a function involving the divided difference of psi functions

REN, X.-Z. and CHEN, Y.-G.; On near-perfect numbers with two distinct prime factors 
RIAZI, A.; see LARKI, H. 206

SANNA, C.; see POLLACK, P. 461

SEO, J.; see BAEK, S. $\quad 474$

SHANG, Y.; Estrada index of general weighted graphs 106

SLAPAR, M.; Cancelling complex points in codimension two 64

SONG, Y.-K.; Remarks on quasi-Lindelöf spaces 507

$\mathrm{SU}, \mathrm{N}$. and WANG, Y.; On the $p$-length and the Wielandt length of a finite $p$-soluble group $\quad 454$

SUGAWA, T.; see KIM, Y. C. $\quad 423$

SUN, L. and XIN, X.; The natural partial order on the semigroup of all transformations of a set that reflect an equivalence relation $\quad 359$

SUN, Z.-W.; On a sequence involving sums of primes 197

TANAKA, Y.; Visible actions on flag varieties of type B and a generalisation of the Cartan decomposition $\quad 81$

TANG, M. and YANG, Z.-J.; Jeśmanowicz' conjecture revisited 487

TUMURBAT, S.; see FRANCE-JACKSON, H. 331

VALJAREVIĆ, D.; see PETROVIĆ, LJ. 17

VINCE, A.; see BARNSLEY, M. F. 267

VUORINEN, M.; see CHEN, SH. 143

WANG, G.; see XU, R. 353

WANG, X.; see CHEN, SH. 143

WANG, Y.; see SU, N. $\quad 454$

WEI, W.; see LI, J. $\quad 390$

WU, J.; see XU, R. 353

XIE, L.-H. and LIN, S.; The Baire property in the remainders of semitopological groups 301

XIN, X.; see SUN, L. $\quad 359$

XU, R., WU, J., WANG, G. and ZHANG, X.; On the sum of powers of the degrees of graphs 353

YALCINER, A.; see LUCA, F. $\quad 510$

YANG, L.; Wiener index and traceable graphs 380

YANG, Z.-J.; see TANG, M. 487

YAO, G.; Hamilton sequences for extremal quasiconformal mappings of doubly-connected domains $\quad 376$

ZHANG, G. R.; see LI, J. J. $\quad 480$

ZHANG, X.; see XU, R. 353 


\section{INFORMATION FOR AUTHORS}

The Bulletin of the Australian Mathematical Society aims at quick publication of original research in all branches of mathematics. To ensure speedy publication, only articles which are sufficiently well presented, able to be published without revision, and which are judged by the Editor (often in consultation with an Associate Editor) to be competitive are refereed. This policy is in the interests of authors, as a quick rejection is better than a slow rejection. The Bulletin receives more than five times the material that can be published, therefore there are many commendable papers not accepted. Editorial decisions on acceptance or otherwise are taken quickly, normally within a month of receipt of the paper. Papers are accepted only after peer review.

Manuscripts are accepted for review with the understanding that the same work is not concurrently submitted elsewhere. For a paper to be acceptable for publication, not only should it contain new and interesting results, but also

(i) the exposition should be clear and attractive, and

(ii) the manuscript should be in publishable form, without revision.

Further information regarding these requirements may be found through our website www.austms.org.au/Bulletin. Authors are asked to avoid, as far as possible, the use of mathematical symbols in the title.

Articles should be prepared in LTEX using $\mathcal{A}_{\mathcal{M}} \mathcal{S}$-LATEX packages and submitted as a PDF file via our journal management system, at www.austms.org.au/Publications/Submissions/BAustMS. This permits authors to track their papers through the editorial process. Recent versions of $\mathrm{T}_{\mathrm{E}} \mathrm{X}$ are able to produce PDF files directly. A LATEX class file for the Bulletin can be downloaded from the website. Authors who need assistance may email the secretary of the Bulletin at jams@ms.unimelb.edu.au.

Authors are advised to keep copies of all files of the submitted article; the Bulletin will not accept responsibility for any loss.

\section{EDITORIAL POLICY}

1. References. Arrange references alphabetically (by surname of the first author) and cite them numerically in the text. Ensure the accuracy of the references: authors' names should appear as in the work quoted. Include in the list of references only those works cited, and avoid citing works which are in preparation or submitted. Where the work cited is not readily accessible (for example, a preprint) a copy of the article should be included with your submission.

\section{Abstracts.}

1. Each paper must include an abstract of not more than 150 words, which should contain a brief but informative summary of the contents of the paper, but no inessential details.

2. The abstract should be self-contained, but may refer to the title.

3. Specific references (by number) to a section, proposition, equation or bibliographical item should be avoided.

3. Subject Classification and Key Words. Authors should include a few key words and phrases and one or more classification numbers, following the American Mathematical Society 2010 Mathematics Subject Classification for all codes. Details of this scheme can be found on the web at www.ams.org/msc.

4. Abstracts of PhD Theses. The Bulletin endeavours to publish abstracts of all accepted Australasian $\mathrm{PhD}$ theses in mathematics. One restriction, however, is that the abstract must be received by the Editor within six months of the degree being approved.

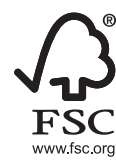

This journal issue has been printed on FSC-certified paper and cover board. FSC is an independent, non-governmental, not-for-profit organisation established to promote the responsible management of the world's forests. Please see www.fsc.org for information. 
On the sum of powers of the degrees of graphs

$X u, R$., Wu, J., Wang, G. E Z Zhang, X.

The natural partial order on the semigroup of all transformations of a set that reflect an equivalence relation

Sun, L. Eं Xin, X.

Isometries between unit spheres of the $\ell^{\infty}$-sum of strictly convex normed spaces

Ding, G.-G. E Li, J.-Z.

Hamilton sequences for extremal quasiconformal mappings of doubly-connected

domains

Yao, G.

Wiener index and traceable graphs

Yang, $L$.

Trace inequalities and a question of Bourin

Hayajneh, S. Ẽ Kittaneh, F.

Slide reduction, successive minima and several applications

$L i, J$. E Wei, W.

The categorification of the Kauffman bracket skein module of $\mathbb{R} P^{3}$

Gabrovšek, B.

Univalence criteria and analogues of the John constant

Kim, Y. C. EV Sugawa, T.

Solutions to polynomial congruences in well-shaped sets

Kerr, $B$.

Commutativity degree of a class of finite groups and consequences

Nath, R. K.

On the $p$-length and the Wielandt length of a finite $p$-soluble group

Su, N. E Wang, $Y$.

Uncertainty principles connected with the Möbius inversion formula

Pollack, P. EO Sanna, C.

Constructions by ruler and compass, together with a fixed conic

Baek, S., Choe, I., Jung, Y., Lee, D. E Seo, J.

1-regular Cayley graphs of valency 7

Li, J. J., Zhang, G. R. E Ling, B.

Jeśmanowicz' conjecture revisited

Tang, M. EO Yang, Z.J.

On the $*$-semisimplicity of the $\ell^{1}$-algebra on an abelian $*$-semigroup

Bhatt, S. J., Dabhi, P. A. Ẽ Dedania, H. V.

Two questions of $\mathbf{L}$. Vaš on $*$-clean rings

Chen, J. Ë Cui, J.

Remarks on quasi-Lindelöf spaces

Song, $Y .-K$.

$\boldsymbol{L}$-functions of elliptic curves and binary recurrences

Luca, F, Oyono, R. E Yalciner, A.

On near-perfect numbers with two distinct prime factors

Ren, X.-Z. EO Chen, Y.-G.

Author Index for Volume 88 